\title{
Blood flow and nutrient exchange across the liver and gut of the dairy cow
}

\author{
Effects of lactation and fasting \\ BY M. A. LOMAX* AND G. D. BAIRD \\ Agricultural Research Council, Institute for Research on Animal Diseases, Compton, \\ Newbury RG16 ONN, Berkshire
}

(Received 14 June 1982 - Accepted 15 December 1982)

1. The rate of blood flow in the portal and hepatic veins, and the net exchange across the gut and liver of volatile fatty acids (VFA), glucose, lactate, pyruvate, amino acids, ketone bodies, glycerol, non-esterified fatty acids (NEFA) and oxygen, were measured in lactating and non-lactating cows $(a)$ in the normal, fed state and $(b)$ before, during and after $6 \mathrm{~d}$ of fasting.

2. Blood flow rate through the liver was $52 \%$ higher in normal, fed, lactating cows as compared with non-lactating cows, and was decreased by fasting in both groups of cows. Portal blood flow rate increased with an increase in metabolizable energy (ME) intake.

3. Lactating, as compared with non-lactating, cows exhibited lower arterial concentrations of glucose and lactate, higher net portal outputs of VFA and ketone bodies, a higher net hepatic output of glucose, and higher net hepatic uptakes of propionate and lactate. The splanchnic outputs of acetate, glucose and hydroxybutyrate were all apparently greater in the lactating cows.

4. Fasting caused a rapid decrease in the blood concentrations of the VFA and an increase in those of glycerol and NEFA. The portal, i.e. gut, outputs of VFA, lactate, ketone bodies, alanine and (serine + threonine), and the portal uptake of $\mathrm{O}_{2}$, were all decreased by fasting. Fasting for $6 \mathrm{~h}$ also decreased the hepatic output of glucose and acetate by 77 and $95 \%$ respectively, increased the hepatic uptake of pyruvate, glycerol and NEFA, and doubled hepatic ketone-body output. The splanchnic output of acetate and glucose and the splanchnic uptake of $\mathrm{O}_{2}$ were also decreased by fasting.

5. The net portal outputs of VFA, lactate and hydroxybutyrate, and the net hepatic output of glucose, were all correlated with $M E$ intake in fed and fasted cows. Hepatic glucose output was also correlated with milk yield.

6. The net hepatic uptake of gluconeogenic precursors measured in this study could account for net hepatic glucose output in the fasted cows, but not in the fed cows. The net hepatic uptake of the ketogenic precursors butyrate and NEFA was sufficient to account for the hepatic output of ketone bodies in both fed and fasted cows, but it is unlikely that the hepatic uptake of ketogenic precursors could also account for the observed hepatic output of acetate.

The gut and liver of the dairy cow can be considered to operate together as a functional unit, termed the splanchnic bed, that supplies nutrients to the remainder of the body. During lactation the splanchnic bed plays a major role in supplying precursors required for milk synthesis. Therefore, changes in metabolite flux across the splanchnic bed will be expected to have major effects on milk synthesis and on the metabolic status of the animal. Alterations in splanchnic metabolism could arise as a result of variation in feed intake or of metabolic events associated with milk production.

In the present study the effects of differences in feed intake were monitored by comparing fed and fasted cows, while the effects of differences in productive demand were monitored by comparing lactating cows with non-lactating cows. Attention has been focused on the behaviour of metabolites of major nutritional importance, including the volatile fatty acids (VFA), glucose, lactate, the ketone bodies and some glucogenic amino acids. Use has been made of appropriately catheterized animals, in which blood flow rate and net metabolite

* Present address: Department of Physiology and Biochemistry, University of Reading, Whiteknights, Reading RG6 2AJ, Berkshire. 
exchange can be measured across the gut and liver (Symonds \& Baird, 1973; Baird et al. 1975).

\section{EXPERIMENTAL}

\section{Animals}

Seven mature non-pregnant Friesian $\times$ Ayrshire dairy cows were used, each of which had been through at least two calvings. At the time of the experiment four of the cows were lactating and three non-lactating. Each cow had been chronically catheterized for the measurement of portal and hepatic production rates by a combination of the methods of Symonds \& Baird (1973) and Baird et al. (1975). The catheterization involved the insertion during surgery of silicone rubber catheters (silastic tubing (Dow Corning); Lepetit Pharmaceuticals, Hounslow, Middx.) into a mesenteric vein, the portal vein at the porta hepatis, a hepatic vein and a carotid artery in each cow. The animals were allowed to recover from surgery for at least 3 weeks and to return to normal feeding before being used in the experiments.

When feeding normally, the non-lactating cows were receiving approximately $5 \mathrm{~kg}$ medium quality hay and $3 \mathrm{~kg}$ dairy concentrates daily and the lactating cows were receiving, in addition, $0.3 \mathrm{~kg}$ dairy concentrates $/ \mathrm{kg}$ milk produced. The daily feed was given in two equal portions, the first at approximately 07.30 hours and the second at approximately 14.30 hours. The feed offered and refused was monitored in two lactating and two non-lactating cows. The metabolizable energy (ME) intake of hay was calculated from the percentage modified acid-detergent fibre using equation no. 68 of Ministry of Agriculture, Fisheries and Food (1975) and the ME intake in concentrates was the sum of the ME values for individual constituents as listed in Ministry of Agriculture, Fisheries and Food (1975). Two lactating and two non-lactating cows were fasted. At the start of fasting the two lactating cows had been calved for 31 and $58 \mathrm{~d}$ respectively. The two non-lactating cows had calved approximately 14 and 9 months respectively before the experiment.

\section{Experimental procedure}

Circulating concentrations and net hepatic and portal production rates of metabolites were measured in both lactating and non-lactating cows in either the normal fed state or before, during and after fasting. The animals were always used for experiment between 10.30 and 12.30 hours. For studies on the effect of fasting, metabolite production rates were first measured in each cow on three separate days while it was feeding normally. The last of these days was then taken as day 0 of the fasting period, and only the morning feed was given on this day. No further food was then given until 6 d later (day 6 of the fasting period) when fasting was ended by the cow being given the afternoon feed. Metabolite production rates were measured on days $1,2,4$ and 6 of the fasting period, counting from day 0 , and then again on days 1 and 3 of the refeeding period. The cow had access to water and minerals at all times.

The procedures for measuring blood flow rate and metabolite production rates on any given day were exactly as described by Baird et al. (1979).

\section{Assays}

Lactate, pyruvate, $\mathrm{D}(-)$-3-hydroxybutyrate and acetoacetate were assayed by the methods used by Baird \& Heitzman (1970), glucose by the method of Bergmeyer et al. (1974), glycerol by the method of Eggstein \& Kuhlmann (1974), alanine by the method of Williamson (1974a), glutamine by the method of Lund (1974), serine and threonine together by the method of Williamson (1974b) and glutamate by the method of Bernt \& Bergmeyer (1974). Free fatty acids (FFA) were determined using thin-layer chromatography as described by Reid et al. (1979). All the previously mentioned compounds were assayed in neutralized 
perchloric-acid extracts of whole blood, except for glycerol and FFA which were assayed in heparinized blood plasma.

Acetate, propionate and butyrate were determined directly in acidified perchloric-acid extracts of blood by gas-liquid chromatography, using a series 204 gas-liquid chromatograph (Pye-Unicam, Cambridge). The column was that employed by Baird et al. (1975). On a number of occasions acetate concentrations were determined enzymically in neutralized perchloric-acid extracts of blood by the method described by Snoswell et al. (1978). Essentially identical results were obtained for the acetate concentrations determined either by gas-liquid chromatography or by the enzymic method. $p$-Aminohippurate was determined in heparinized plasma by the autoanalytical method of Harvey \& Brothers (1962).

The oxygen concentration in whole blood was calculated from the $\mathrm{pO}_{2}$, the $\mathrm{pCO}_{2}$, the $\mathrm{pH}$ and the haemoglobin content of the blood. Blood samples for determination of $\mathrm{pO}_{2}$ and $\mathrm{pCO}_{2}$ were collected in heparinized syringes and cooled in ice before assay. The partial pressures of $\mathrm{O}_{2}$ and $\mathrm{CO}_{2}$ were then determined, as soon as possible after collection of the blood samples, using an IL 213-227 pH/Blood Gas Analyser (Instrumentation Laboratory (UK) Ltd, Altrincham, Cheshire). Haemoglobin content, and also packed cell volume, were determined on separate samples of blood, taken simultaneously, using a Coulter Counter (Coulter Diagnostics Inc., Hialeah, Florida). The $\mathrm{pO}_{2}$ values were subsequently converted in $\mathrm{mmol} / 1$ whole blood using the relevant values of Bock et al. (1924).

\section{Statistics}

Significances of differences between means of measurements for lactating and non-lactating cows were determined by Student's $t$ test. Standard errors of differences were determined for means obtained for the fed state, and for days, 1,2, 4 and 6 of fasting, and days 1 and 3 of refeeding. These standard errors were then used to establish significant differences between fed means on the one hand and means observed during fasting or refeeding on the other. The procedure involved adjusting the data by subtracting the pre-fasting value from each observation made during the fasting and refeeding periods and then analysing by a split-plot analysis of variance with lactation group as a main-plot effect and day of sampling as a sub-plot effect.

\section{RESULTS}

\section{Blood flow across the gut and liver}

On average, the rates of blood flow through the portal and hepatic veins, i.e. across the gut and liver respectively, were $56 \%$ higher in lactating cows as compared with non-lactating cows (Table 1). However, there was no clear effect of lactation on the derived values for blood flow in the hepatic artery, or on the percentage contribution of portal flow to hepatic flow (Table 1). After $2 \mathrm{~d}$ of fasting there were significant decreases in portal flow in both lactating and non-lactating cows, and in hepatic artery flow in the lactating cows (Table 2). In both the lactating and non-lactating cows portal flow had decreased to what appeared to be a plateau level of $8-91 / \mathrm{min}$ after $4 \mathrm{~d}$ of fasting. Although there was clear evidence of an increase in blood flow rate during the $3 \mathrm{~d}$ refeeding period, prefasting values were not achieved.

\section{Comparison of metabolism in fed cows}

The results are recorded in Table 3. The arterial concentrations of glucose and lactate were significantly lower in the lactating cows than in the non-lactating cows (see also Baird et al. 1980). However, there were no clear effects of lactation on the portal concentrations of propionate and butyrate, or on the arterial concentrations of acetate and hydroxybutyrate. Insufficient values were obtained to permit any conclusions concerning effects of lactation on the arterial concentrations of acetoacetate, glycerol, FFA and $\mathrm{O}_{2}$. 
Table 1. Rate of blood flow $(l / \mathrm{min})$ in the hepatic vein, portal vein and hepatic artery in lactating and non-lactating cows

(Mean values with their standard errors; the number of animals is in parentheses. The values obtained for individual cows were, in turn, means of several observations)

\begin{tabular}{|c|c|c|c|c|c|c|c|c|}
\hline \multirow[b]{2}{*}{ Cow status } & \multicolumn{2}{|c|}{ Hepatic vein } & \multicolumn{2}{|c|}{ Portal vein } & \multicolumn{2}{|c|}{ Hepatic artery } & \multicolumn{2}{|c|}{$\frac{\text { Portal vein flow }}{\text { Hepatic vein flow }} \times 100$} \\
\hline & Mean & $\mathbf{S E}$ & Mean & SE & Mean & $\mathrm{SE}$ & Mean & SE \\
\hline Lactating (4) & $28 \cdot 5^{* * *}$ & $1 \cdot 4$ & $23 \cdot 2^{* * *}$ & 1.8 & $5 \cdot 4$ & $1 \cdot 2$ & $81 \cdot 0$ & $4 \cdot 2$ \\
\hline Non-lactating (3) & $18 \cdot 7$ & 0.7 & $14 \cdot 5$ & 0.7 & $4 \cdot 2$ & 0.2 & $77 \cdot 3$ & $1 \cdot 4$ \\
\hline
\end{tabular}

Mean values for lactating cows were significantly different from those for non-lactating cows: ${ }^{* * * P<0.001}$.

Table 2. Effect of fasting on the rate of blood flow (l/min) in (a) the portal vein and (b) hepatic artery in two lactating and two non-lactating cows

(Mean values for two cows)

\begin{tabular}{|c|c|c|c|c|c|c|c|c|c|}
\hline \multirow{2}{*}{\multicolumn{2}{|c|}{ Cow status }} & \multirow[b]{2}{*}{ Fed } & \multicolumn{4}{|c|}{ Period of food deprivation (d) } & \multicolumn{2}{|c|}{ Period of refeeding $(d)$} & \multirow{2}{*}{$\begin{array}{l}\text { Standard error } \\
\text { - of difference } \\
\text { between means }\end{array}$} \\
\hline & & & 1 & 2 & 4 & 6 & 1 & 3 & \\
\hline (a) & $\begin{array}{l}\text { Lactating } \\
\text { Non-lactating }\end{array}$ & $\begin{array}{l}18 \cdot 67 \\
15 \cdot 51\end{array}$ & $\begin{array}{l}13 \cdot 72 \\
12 \cdot 05\end{array}$ & $\begin{array}{l}11 \cdot 47^{*} \\
10 \cdot 03^{*}\end{array}$ & $\begin{array}{l}9 \cdot 03^{* *} \\
8 \cdot 30^{*}\end{array}$ & $\begin{array}{l}8 \cdot 80^{* *} \\
8 \cdot 65^{*}\end{array}$ & $\begin{array}{l}9 \cdot 29 * * \\
12.76\end{array}$ & $\begin{array}{l}14 \cdot 31 \\
14 \cdot 81\end{array}$ & $\begin{array}{l}2 \cdot 73 \\
2 \cdot 73\end{array}$ \\
\hline (b) & $\begin{array}{l}\text { Lactating } \\
\text { Non-lactating }\end{array}$ & $\begin{array}{l}7.99 \\
4.35\end{array}$ & $\begin{array}{l}4.28^{*} \\
1.59\end{array}$ & $\begin{array}{l}3.69^{*} \\
4 \cdot 47\end{array}$ & $\begin{array}{l}2 \cdot 26^{* *} \\
3 \cdot 64\end{array}$ & $\begin{array}{l}1 \cdot 60^{* *} \\
1 \cdot 13\end{array}$ & $\begin{array}{l}2 \cdot 52^{* *} \\
2 \cdot 52\end{array}$ & $\begin{array}{l}4.96 \\
1.75\end{array}$ & $\begin{array}{l}1.47 \\
1.47\end{array}$ \\
\hline
\end{tabular}

Mean values for fasted cows were significantly different from those for fed cows: $\quad * P<0.05, \quad * * P<0.01$.

There were net outputs of acetate, propionate, butyrate, lactate, hydroxybutyrate and acetoacetate from the gut in both groups of cows. In general, the magnitudes of these net outputs were greater in the lactating group, but statistical significance for the difference was not achieved in every instance. In both the lactating and non-lactating cows there was a large net uptake of $\mathrm{O}_{2}$ by the gut and a small net uptake of glucose. There was little net exchange of glycerol across the gut in either group. In two lactating cows there was a net output of FFA by the gut, while in two non-lactating cows there was a net uptake.

In both groups of cows there were net hepatic outputs of acetate, glucose and hydroxybutyrate and net hepatic uptakes of propionate, butyrate, lactate, acetoacetate, glycerol, FFA and $\mathrm{O}_{2}$. The hepatic output of glucose, and hepatic uptake of the potentially-gluconeogenic precursors, propionate and lactate, were all significantly higher in the lactating cows than in the non-lactating cows. While the hepatic uptake of butyrate and output of hydroxybutyrate also appeared to be higher in the lactating cows, the differences were not statistically significant. The hepatic outputs of acetate were very similar in the two groups.

In both the lactating and non-lactating cows there were net outputs from the splanchnic bed of acetate, propionate, butryate, glucose and hydroxybutyrate (Table 3 ). The quantitatively most important output, whether assessed on a molar or carbon basis, was that of acetate. The outputs of glucose and hydroxybutyrate were also substantial. The outputs of all these latter three compounds were greater during lactation, although significance for the difference was only obtained for acetate. The only compound taken up 


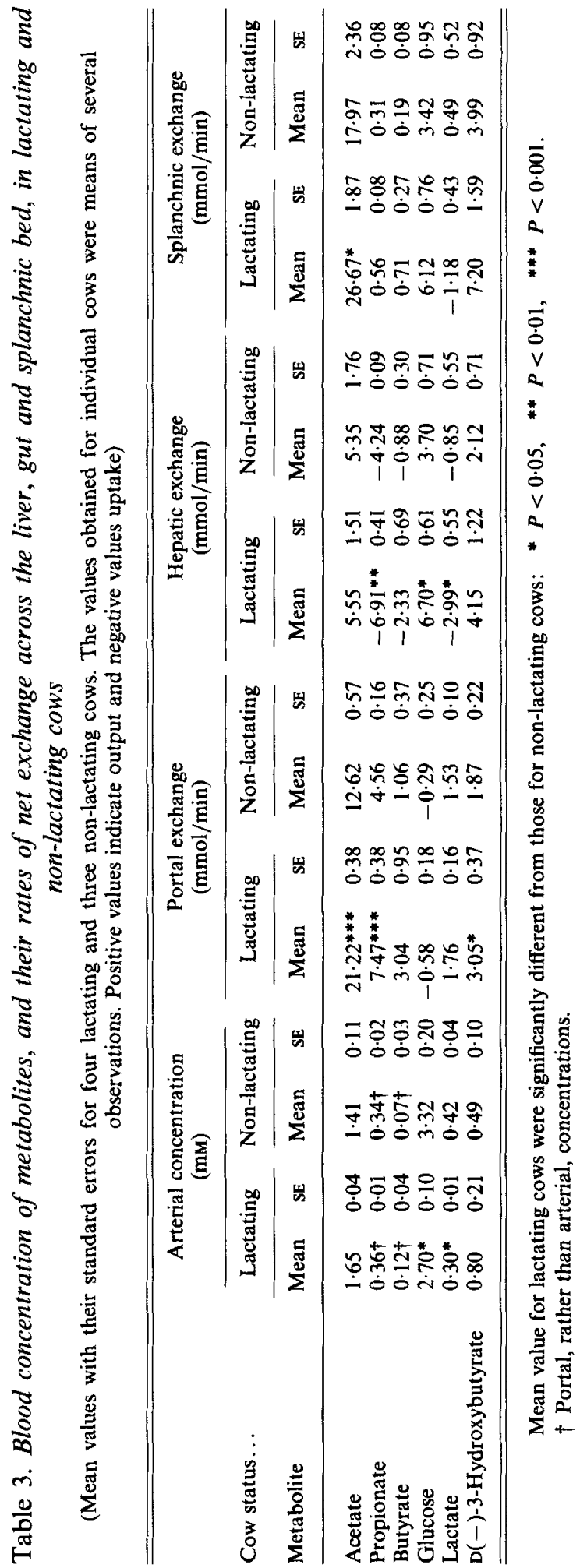


by the splanchnic bed in any large amount was $\mathrm{O}_{2}$. While there was a net uptake of lactate by the splanchnic bed in the lactating cows, there was a net output in the non-lactating animals (see also Baird et al. 1980). Conversely, there was a net output of FFA in the lactating group, and a net uptake in the non-lactating group.

\section{Effects on metabolism of fasting and subsequent refeeding}

Despite the differences between lactating and non-lactating cows that are revealed in Tables $1-3$, it was observed that, in general, fasting and subsequent refeeding had rather similar effects on metabolite concentration and flux in both groups of cows. Because of this, the values from the two lactating cows and two non-lactating cows that were subjected to fasting and refeeding were pooled, and these pooled values are recorded in Tables 4-7. Differences between the two groups of cows in the effects of fasting and refeeding on lactate and pyruvate metabolism have been dealt with elsewhere (Baird et al. 1980).

A striking and rapid effect of fasting was to cause major decreases in the blood concentrations of the three VFA. Thus, as Table 4 shows, after only $24 \mathrm{~h}$ of fasting the arterial concentration of acetate and the portal concentrations of propionate and butyrate had decreased by approximately $75 \%$ in each instance. After $6 \mathrm{~d}$ of fasting the blood concentrations of acetate and propionate had decreased over all by 90 and $97 \%$ respectively, while butyrate could no longer be detected in portal blood. In agreement with many other studies (e.g. Bergman et al. 1968, 1970), the blood concentrations of glycerol and FFA rose rapidly during fasting to 300 and $500 \%$ respectively of the corresponding values in the fed state.

Fasting had relatively little effect on the mean concentrations of glucose, lactate and pyruvate (but see Baird et al. 1980), and $\mathrm{O}_{2}$. During fasting there was a general tendency for the concentrations of the five amino acids to decline, although significance was only achieved for the falls in the concentrations of (serine + threonine) and glutamine (Table 4). Mean hydroxybutyrate concentration changed little during fasting. While mean acetoacetate concentration tended to increase as fasting progressed, significance for the increase was only obtained on day 6.

Immediate effects of refeeding included increases in the blood concentrations of the VFA, and decreases in those of hydroxybutyrate, acetoacetate and the FFA. The concentrations of some of the metabolites had still not returned to prefasting values after $72 \mathrm{~h}$ of refeeding (Table 4).

Fasting either abolished or severely decreased output from the gut (i.e. net portal output) of the three VFA, lactate, hydroxybutyrate, acetoacetate, alanine and (serine + threonine) (Table 5). The decreases in gut output occurred rapidly, since after $24 \mathrm{~h}$ of fasting gut outputs of acetate, propionate, butyrate and ketone bodies were already only 30, 18, 18 and $21 \%$ respectively of the values in the fed state. As fasting progressed, output of ketone bodies from the gut was transformed into a small net uptake. Other changes induced by fasting included a decline in $\mathrm{O}_{2}$ uptake by the gut to only $40 \%$ of the fed value, and a switch to a small net output of glycerol. During refeeding there was, as would be expected, an increase in output of nutrients from the gut. However, even after $72 \mathrm{~h}$ of refeeding, gut function had by no means been restored to normal. For example, the outputs of acetate and hydroxybutyrate were still only approximately $25 \%$, and $\mathrm{O}_{2}$ uptake still only $68 \%$, of prefasting values.

Table 6 shows that during fasting, hepatic output of glucose and acetate decreased by some 77 and $95 \%$ respectively. By contrast, fasting doubled the output of ketone bodies. This was due to the combination of a small increase in hydroxybutyrate output and a change in the direction of net exchange of acetoacetate across the liver from uptake to output. During fasting, hepatic uptake of propionate and butyrate ceased, since these compounds were no longer being supplied from the gut. However, the uptake of lactate (see also Baird 
Table 4. Effect of fasting and subsequent refeeding on blood concentrations ( $\mathrm{m} M$ in whole blood) of metabolites in dairy cows

(Mean values for four cows, two of which were lactating and two non-lactating, for arterial blood, except for propionate and butyrate, which are for portal blood)

\begin{tabular}{|c|c|c|c|c|c|c|c|c|}
\hline \multirow[b]{2}{*}{ Metabolite } & \multirow[b]{2}{*}{ Fed } & \multicolumn{4}{|c|}{ Period of fasting (d) } & \multicolumn{2}{|c|}{$\begin{array}{l}\text { Period of } \\
\text { refeeding (d) }\end{array}$} & \multirow{2}{*}{$\begin{array}{l}\text { Standard error } \\
\text { of difference } \\
\text { between means }\end{array}$} \\
\hline & & 1 & 2 & 4 & 6 & 1 & 3 & \\
\hline Acetate & 1.55 & $0 \cdot 38^{* * *}$ & $0 \cdot 28^{* * *}$ & $0 \cdot 17^{* * *}$ & $0 \cdot 16^{* * *}$ & $0 \cdot 42^{* * *}$ & $0.62^{* * *}$ & 0.08 \\
\hline Propionate & 0.35 & $0.08^{* * *}$ & $0 \cdot 06^{* * *}$ & $0.02^{* * *}$ & $0 \cdot 01^{* * *}$ & $0 \cdot 18^{* *}$ & $0.23^{*}$ & 0.06 \\
\hline Butyrate & 0.08 & $0 \cdot 02^{*}$ & $0^{* * *}$ & $0^{* *}$ & $0^{* *}$ & 0.03 & 0.09 & 0.02 \\
\hline Glucose & 3.00 & $3 \cdot 36$ & $2 \cdot 92$ & $2 \cdot 70$ & $2 \cdot 88$ & $3 \cdot 41$ & $2 \cdot 89$ & $0 \cdot 31$ \\
\hline Lactate & 0.39 & $0 \cdot 32$ & $0 \cdot 29$ & $0 \cdot 39$ & 0.45 & 0.65 & 0.30 & $0 \cdot 11$ \\
\hline Pyruvate & 0.03 & 0.02 & 0.02 & 0.02 & 0.03 & 0.05 & 0.02 & $0 \cdot 01$ \\
\hline Alanine & 0.17 & $0 \cdot 11$ & $0 \cdot 12$ & $0 \cdot 10$ & $0 \cdot 10$ & $0 \cdot 11$ & $0 \cdot 15$ & 0.03 \\
\hline Serine + threonine & 0.14 & $0 \cdot 10^{*}$ & $0 \cdot 12$ & $0.07^{* *}$ & $0 \cdot 09^{* *}$ & $0 \cdot 11$ & 0.13 & 0.02 \\
\hline Glutamate & 0.06 & 0.06 & 0.06 & 0.04 & 0.04 & 0.03 & 0.05 & 0.01 \\
\hline Glutamine & $0 \cdot 14$ & $0 \cdot 10$ & $0 \cdot 13$ & $0.06^{*}$ & $0 \cdot 08$ & $0 \cdot 11$ & $0 \cdot 10$ & 0.03 \\
\hline $\mathrm{D}(-)$-3-Hydroxybutyrate & 0.62 & 0.39 & $0 \cdot 58$ & 0.83 & 0.88 & $0 \cdot 28^{*}$ & 0.46 & $0 \cdot 14$ \\
\hline Acetoacetate & 0.03 & 0.03 & $0 \cdot 06$ & $0 \cdot 13$ & $0 \cdot 15^{*}$ & 0.02 & 0.04 & 0.05 \\
\hline Glycerol $\dagger$ & 0.02 & $0.05^{*}$ & $0 \cdot 06^{* *}$ & $0.06^{*}$ & $0.06^{*}$ & 0.05 & 0.03 & 0.01 \\
\hline Free fatty acids $\uparrow$ & $0 \cdot 22$ & 0.56 & $0.63^{*}$ & $0 \cdot 85^{*}$ & $1 \cdot 10^{*}$ & 0.49 & 0.43 & $0 \cdot 18$ \\
\hline Oxygen & $5 \cdot 34$ & $5 \cdot 33$ & $5 \cdot 23$ & $5 \cdot 34$ & $5 \cdot 59$ & $6 \cdot 45^{* *}$ & $5 \cdot 23$ & 0.33 \\
\hline
\end{tabular}

Mean values for fasted cows were significantly different from those for fed cows: $* P<0.05$, ** $P<0.01$, *** $P<0.001$.

$\dagger \mathrm{mM}$ in plasma.

et al. 1980) remained relatively constant on average. Hepatic uptake of the amino acids other than glutamate also remained approximately at the fed level for the first $4 \mathrm{~d}$ of fasting. Hepatic uptake of glycerol and FFA increased to 433 and $347 \%$ respectively of the prefasting values. This was doubtless due to an elevated supply of these compounds, arising in turn from increased lipid mobilization. Finally, hepatic consumption of $\mathrm{O}_{2}$ decreased by approximately $70 \%$ during fasting.

As Table 6 shows, quite marked changes in net hepatic metabolism had already taken place after only $1 \mathrm{~d}$ of fasting. These changes included $80 \%$ decreases in uptake of propionate and butyrate and a $45 \%$ decrease in output of glucose. Also at this time, acetoacetate uptake had decreased by $80 \%$ and $\mathrm{O}_{2}$ uptake by $47 \%$, while hepatic uptake of glycerol and FFA had already risen to values as high as any achieved during the remainder of the fasting period.

It was apparent that more than $3 \mathrm{~d}$ of refeeding would have been required to restore the indices of hepatic metabolism to prefasting values. Nevertheless, the $3 \mathrm{~d}$ were sufficient to elicit marked increases in hepatic uptake of butyrate and propionate, and hepatic output of glucose. Increases in these factors were in fact already evident after only $24 \mathrm{~h}$ of refeeding, as were decreases in the hepatic output of hydroxybutyrate and acetoacetate, and increases in the uptake of lactate and pyruvate (Table 6).

After only $24 \mathrm{~h}$ of fasting, net splanchnic output of acetate and glucose had decreased by 82 and $54 \%$ respectively, while net uptake of $\mathrm{O}_{2}$ had decreased by $40 \%$. On the other hand, uptake of the gluconeogenic precursors lactate and pyruvate had increased by 450 and $160 \%$ respectively (Table 7 ). On average, over the whole fasting period, net splanchnic uptakes of glycerol and FFA were increased by approximately 150 and $400 \%$ respectively. Net output of ketone bodies actually decreased somewhat (see also Baird et al. 1979). As with gut and liver metabolism, net splanchnic metabolism had by no means returned to normal after the $72 \mathrm{~h}$ of refeeding. 


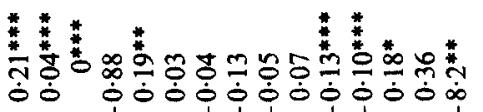

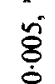

草事

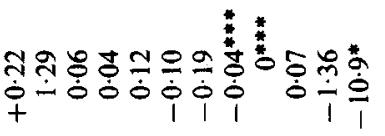

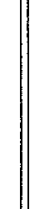
v

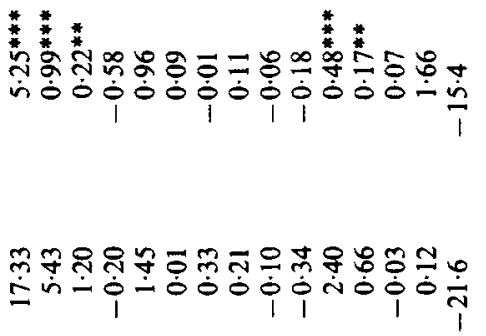
글 


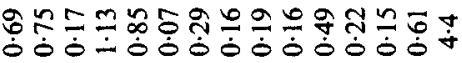

离

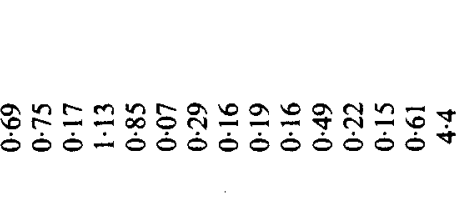

****

*ึ่

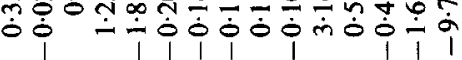

\begin{tabular}{l}
$\dot{8}$ \\
$\dot{0}$ \\
$v$ \\
$a$ \\
$*$ \\
$*$ \\
$\dot{0}$ \\
$\dot{0}$ \\
$v$ \\
2 \\
$*$ \\
\multirow{2}{*}{} \\
$\dot{0}$ \\
$v$
\end{tabular}

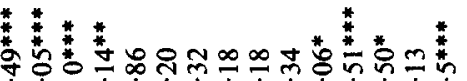
近

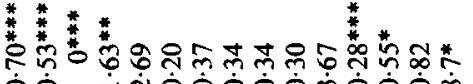

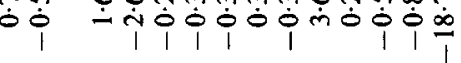

$\stackrel{2}{2}$

8

:

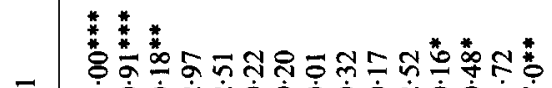

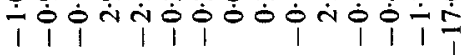

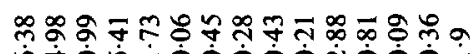

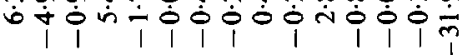


Table 7. Effect of fasting and subsequent refeeding on net exchange of metabolites (mmol/in whole blood) across the splanchnic bed in dairy cows in vivo

(The values are the algebraic sums of the mean rates of net exchange across the gut and liver for four cows, two of which were lactating and two non-lactating, as recorded in Tables 5 and 6 . Positive values indicate output and negative values uptake)

\begin{tabular}{|c|c|c|c|c|c|c|c|}
\hline \multirow[b]{2}{*}{ Metabolite } & \multirow[b]{2}{*}{ Fed } & \multicolumn{4}{|c|}{ Period of fasting (d) } & \multicolumn{2}{|c|}{ Period of refeeding (d) } \\
\hline & & 1 & 2 & 4 & 6 & 1 & 3 \\
\hline Acetate & $23 \cdot 71$ & $4 \cdot 25$ & 1.74 & 0.66 & 0.56 & 3.66 & $5 \cdot 88$ \\
\hline Propionate & 0.45 & 0.08 & -0.35 & 0 & $0 \cdot 02$ & $0 \cdot 17$ & 0.41 \\
\hline Butyrate & 0.21 & 0.04 & 0 & 0 & 0 & 0.06 & 0.23 \\
\hline Glucose & $5 \cdot 21$ & $2 \cdot 39$ & $1 \cdot 58$ & 0.68 & 0.35 & $3 \cdot 84$ & $2 \cdot 30$ \\
\hline Lactate & -0.28 & -1.55 & $-1 \cdot 40$ & $-1 \cdot 78$ & -1.64 & $-2 \cdot 44$ & $-1 \cdot 15$ \\
\hline Pyruvate & -0.05 & $-0 \cdot 13$ & -0.14 & $-0 \cdot 15$ & -0.17 & -0.33 & -0.22 \\
\hline Alanine & $-0 \cdot 12$ & $-0 \cdot 21$ & -0.33 & -0.29 & $-0 \cdot 18$ & -0.01 & -0.04 \\
\hline Serine + threonine & -0.07 & 0.12 & -0.22 & -0.07 & -0.25 & ND & ND \\
\hline Glutamate & 0.33 & 0.26 & $0 \cdot 24$ & $0 \cdot 18$ & $0 \cdot 10$ & 0.57 & 0.28 \\
\hline Glutamine & -0.55 & 0.35 & -0.49 & -0.40 & -0.03 & -0.35 & -0.22 \\
\hline$D(-)-3$-Hydroxybutyrate & $5 \cdot 28$ & 3.00 & 3.63 & 3.92 & 3.03 & 1.64 & $2 \cdot 73$ \\
\hline Acetoacetate & $-0 \cdot 15$ & 0.01 & 0.28 & $0 \cdot 39$ & 0.43 & 0 & $0 \cdot 15$ \\
\hline Glycerolt & $-0 \cdot 12$ & -0.41 & -0.48 & -0.32 & $-0 \cdot 30$ & -0.15 & $-0 \cdot 14$ \\
\hline Free fatty acids $\dagger$ & -0.24 & -0.06 & $-2 \cdot 18$ & $-0 \cdot 80$ & $-1 \cdot 25$ & ND & ND \\
\hline Oxygen & $-53 \cdot 5$ & $-32 \cdot 4$ & $-29 \cdot 5$ & $-20 \cdot 8$ & -17.9 & $-27 \cdot 7$ & $-32 \cdot 8$ \\
\hline
\end{tabular}

$\dagger \mathrm{mmol} / \mathrm{min}$ in plasma.

ND, not determined.

\section{DISCUSSION}

Regulation of the rate of blood flow through the portal vein

A number of workers have demonstrated a relationship between portal blood flow rate and feed intake (Bensadoun et al. 1962; Katz \& Bergman, 1969; Huntington et al. 1981). Webster et al. (1975) found that, in the sheep, blood flow through the portal vein was curvilinearly related to intake of ME. It seems probable, therefore, that blood flow through the portal vein was higher in the lactating cows than in the non-lactating cows in the present study simply because the lactating cows were consuming more food. Support for this conclusion is given in Fig. 1(a), which uses values derived from both lactating and non-lactating cows in the present study, together with values from other studies, to show how portal flow increased with increase in the intake of ME.

Weekes \& Webster (1975) reported that portal blood flow in sheep was positively correlated with the rates at which VFA were infused into the rumen, and also with the rates of net appearances of propionate and lactate in portal blood. In the present study it was also possible to correlate portal flow rate not only with the net portal output of VFA, but also with that of hydroxybutyrate and lactate (see Lomax, 1979). However, in our hands, infusions of propionate, butyrate or lactate into the mesenteric vein at $10,3.5$ and $2.5 \mathrm{mmol} / \mathrm{min}$ respectively had no effect on portal flow rate in either lactating or non-lactating cows (Lomax, 1979). This suggests that in the cow, at least, nutrient concentrations within, and rate of passage along, the portal vein may not be an important factor in determining the rate of portal blood flow. 
Metabolite exchange across the gut

Several previous studies have demonstrated proportionality between the level of feed intake and the rate of production of nutrients within the rumen. For example, in a study of lactating and non-lactating cows, Wiltrout \& Satter (1972) found that with feed intakes of 9.5 and $17 \mathrm{~kg}$ dry matter $/ \mathrm{d}$ the rates of acetate production within the rumen were 29.2 and $53.5 \mathrm{mmol} / \mathrm{min}$ respectively. Other workers have demonstrated proportionality between the level of feed intake and the rate of production of propionate within the rumen of both cattle (Bauman et al. 1971; Herbein et al. 1978) and sheep (Steel \& Leng, 1973). Values obtained with both fed and fasted lactating and non-lactating cows and sheep reveal positive relationships between ME intake and the rates of net portal appearance of VFA, hydroxybutyrate and lactate (Figs. $1 b-f$ ). Hydroxybutyrate appearing in the portal vein is believed to arise from the metabolism of butyrate during absorption across the rumen epithelium (Pennington, 1952). It would be expected, therefore, that the portal output of hydroxybutyrate would be proportional to feed intake.

Striking observations in the present study were the rapidity with which the absorption of metabolites from the gut declined during fasting, and the tardiness with which normal rates of absorption were restored during refeeding. These observations clearly have implications in the elucidation of the role played by short periods of undernutrition in the aetiology of metabolic disorders of cattle (cf. Baird, 1977).

\section{Metabolite exchange across the liver}

Two major determinants of hepatic glucose output in ruminants are energy intake in the diet, and level of productivity (Wiltrout \& Satter, 1972; Herbein et al. 1978). Fig. $1(\mathrm{~g})$ demonstrates that hepatic glucose output is positively related to ME intake in both sheep and cattle. In the present study, too, hepatic glucose output was found to be linearly related to milk yield in both fed and fasted cows (glucose output $(\mathrm{mmol} / \mathrm{min})=0.41 \times$ yield $(\mathrm{kg} / \mathrm{d})$ $-0.32(r=0.850 ; P<0.001))$.

Using the values relating to net hepatic metabolism given in Table 6 , one can calculate the maximum contribution that assimilated precursors could make to the observed net output of compounds arising within the liver. Such a calculation assumes that liver metabolism was in a steady-state at the time of sampling. Table 8 lists the maximum percentage contribution that those gluconeogenic precursors, whose uptake by the liver was recorded, could have made to net hepatic output of glucose in the fed state and during fasting and refeeding. In the fed state, the quantitatively most important potential precursor of glucose was propionate, which could have accounted for approximately $50 \%$ of glucose output. This value is in approximate agreement with previous estimates of the contribution of propionate to glucose entry rate in cattle (e.g. Wiltrout \& Satter, 1972), but of course makes no allowance for the fact that assimilated propionate would probably be used for other purposes besides glucose synthesis. In this study, all the measured gluconeogenic precursors together could only have accounted for a maximum of $72 \%$ of hepatic glucose output in the fed state. During fasting the potential contribution of propionate to hepatic glucose output decreased to insignificance. By contrast, that of the other gluconeogenic precursors increased, because output of glucose declined while uptake of these precursors either increased or was maintained at prefasting levels. Between days 2 and 6 of fasting, the observed uptake of gluconeogenic precursors, which at this time must have been derived almost entirely from endogenous sources, was sufficient to account for all the glucose output from the liver. Garber et al. (1974) were also unable to equate glucose output with precursor 
Table 8. Effect of fasting and subsequent refeeding on maximum possible contribution $(\%)$ of assimilated precursors to output of glucose by the liver in dairy cows

(The values are in each case the rate of uptake by the liver expressed as a percentage of $2 \times$ hepatic glucose output. The rates of hepatic uptake are recorded in Table 6 )

\begin{tabular}{|c|c|c|c|c|c|c|c|}
\hline \multirow[b]{2}{*}{ Precursor } & \multirow[b]{2}{*}{ Fed } & \multicolumn{4}{|c|}{ Period of fasting (d) } & \multicolumn{2}{|c|}{$\begin{array}{l}\text { Period of } \\
\text { refeeding (d) }\end{array}$} \\
\hline & & 1 & 2 & 4 & 6 & 1 & 3 \\
\hline Propionate & $46 \cdot 0$ & $15 \cdot 3$ & $16 \cdot 5$ & $2 \cdot 2$ & 0.8 & 16.9 & $40 \cdot 2$ \\
\hline Lactate & $16 \cdot 0$ & $42 \cdot 3$ & 82.5 & 81.6 & $74 \cdot 4$ & $54 \cdot 4$ & $28 \cdot 7$ \\
\hline Pyruvate & 0.6 & $3 \cdot 7$ & $6 \cdot 1$ & 8.8 & $8 \cdot 1$ & $4 \cdot 2$ & $3 \cdot 4$ \\
\hline Amino acids* & $8 \cdot 6$ & $6 \cdot 1$ & $31 \cdot 3$ & $36 \cdot 8$ & $14 \cdot 6$ & $4 \cdot 4$ & $4 \cdot 3$ \\
\hline Glycerol & $0 \cdot 8$ & $8 \cdot 1$ & $16 \cdot 9$ & 21.9 & $19 \cdot 5$ & $2 \cdot 6$ & $3 \cdot 4$ \\
\hline Total & $72 \cdot 0$ & $75 \cdot 5$ & $153 \cdot 3$ & $151 \cdot 3$ & $117 \cdot 4$ & $82 \cdot 5$ & $80 \cdot 0$ \\
\hline
\end{tabular}

* Alanine + glycine + serine + threonine.

Table 9. Effect of fasting and subsequent refeeding on maximum possible contribution $(\%)$ of assimilated precursors to output of ketone bodies by the liver in dairy cows

(The values for butyrate and free fatty acids are butyrate uptake and ( $4 \times$ uptake of free fatty acids) respectively, expressed in each case as a percentage of the net output of ketone bodies. The rates of hepatic uptake are recorded in Table 6)

\begin{tabular}{|c|c|c|c|c|c|c|c|}
\hline \multirow[b]{2}{*}{ Precursor } & \multirow[b]{2}{*}{ Fed } & \multicolumn{4}{|c|}{ Period of fasting (d) } & \multicolumn{2}{|c|}{ Period of refeeding (d) } \\
\hline & & 1 & 2 & 4 & 6 & 1 & 3 \\
\hline $\begin{array}{l}\text { Butyrate } \\
\text { Free fatty acids }\end{array}$ & $\begin{array}{l}47.8 \\
69 \cdot 6\end{array}$ & $\begin{array}{r}7.6 \\
291.5\end{array}$ & $\begin{array}{l}0 \\
83 \cdot 0\end{array}$ & $\begin{array}{c}0 \\
98 \cdot 9\end{array}$ & $\begin{array}{c}0 \\
174.5\end{array}$ & $\begin{array}{r}14 \cdot 2 \\
\mathrm{ND}\end{array}$ & $\begin{array}{r}44.0 \\
\text { ND }\end{array}$ \\
\hline Total & 117.4 & 299.1 & $83 \cdot 0$ & 98.9 & 174.5 & ND & ND \\
\hline
\end{tabular}

ND, not determined.

uptake in livers of fed humans. The deficit could possibly be accounted for by hepatic glycogenolysis, or be due to the fact that amino acids not measured in the present study made a substantial contribution to gluconeogenesis. In the latter instance the contribution of amino acids to glucose synthesis would presumably have been much greater than the $2 \%$ proposed by Bruckental et al. (1980) for high-yielding cows.

Table 9 records the maximum percentage contributions that assimilated butyrate and FFA could have made to the net hepatic output of ketone bodies in the fed state and during fasting. In the fed cows the total uptake of butyrate and FFA was more than adequate to account for ketone-body output. During fasting the contribution of butyrate ceased. Nevertheless, the increase that occurred in hepatic uptake of FFA at this time was on average sufficient to account for the output of ketone bodies.

Inspection of Tables 6 and 9 indicates that the combined hepatic uptake of butyrate and FFA could only have accounted for output of acetate as well as ketone bodies on days 1 and 6 of fasting. In any case, there clearly was no positive correlation between hepatic acetate output and FFA uptake, since the former decreased during fasting while the latter increased. This conclusion is contrary to that of Costa et al. (1976), but is supported by the recent finding of Pethick et al. (1981) that there is no significant increase in hepatic acetate output when diabetic sheep are fasted. 


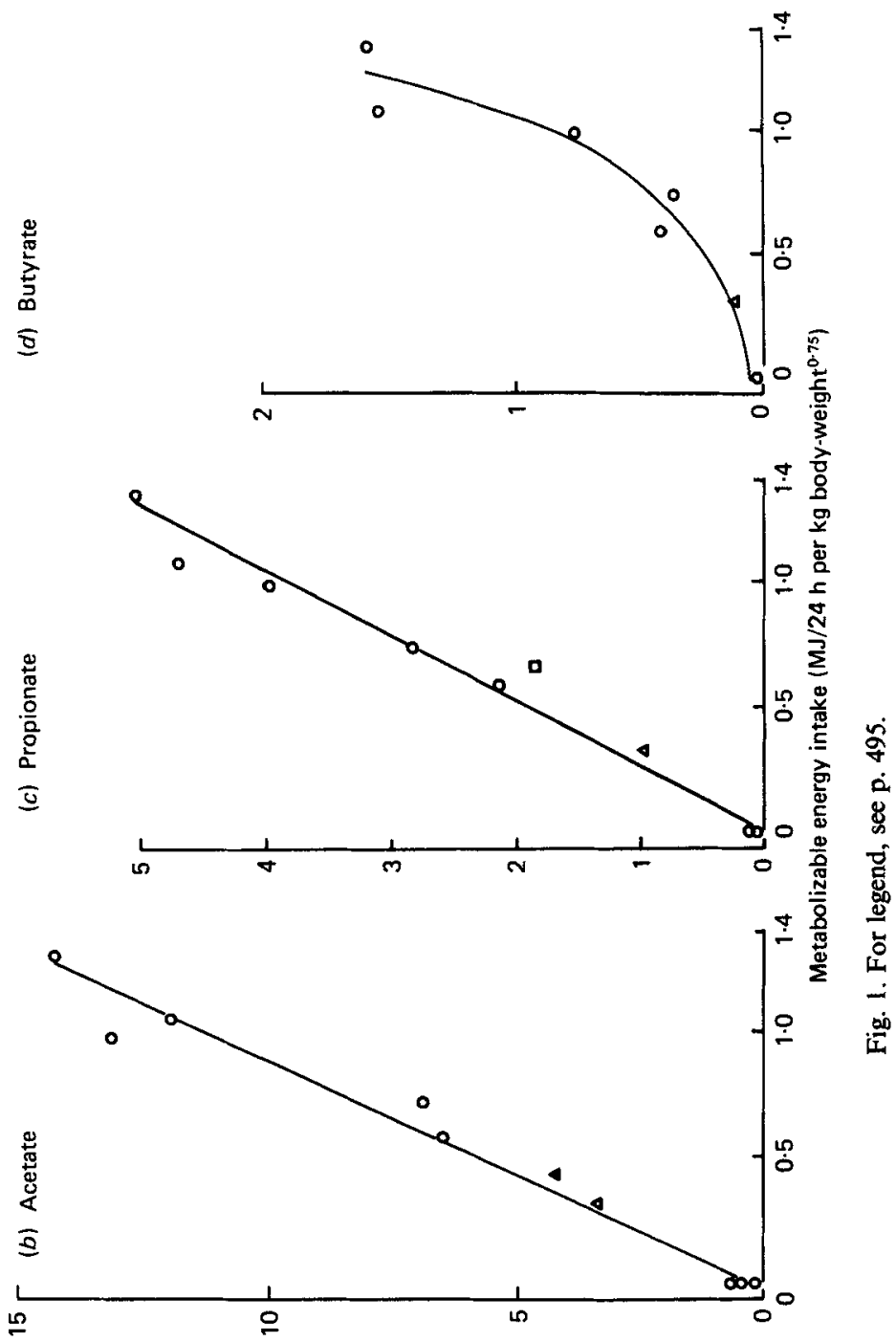

(sc.0+46!am-Apoq 6y sad $4 /$ /oum) Indino jezlod IaN

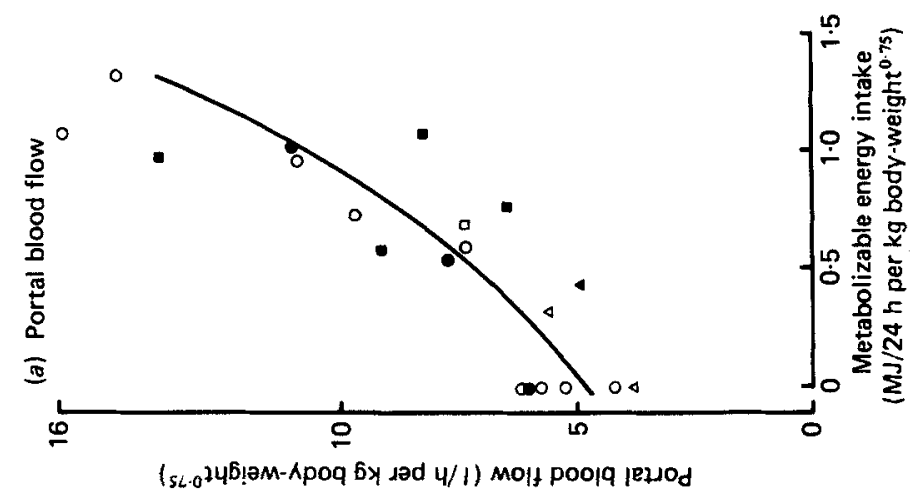



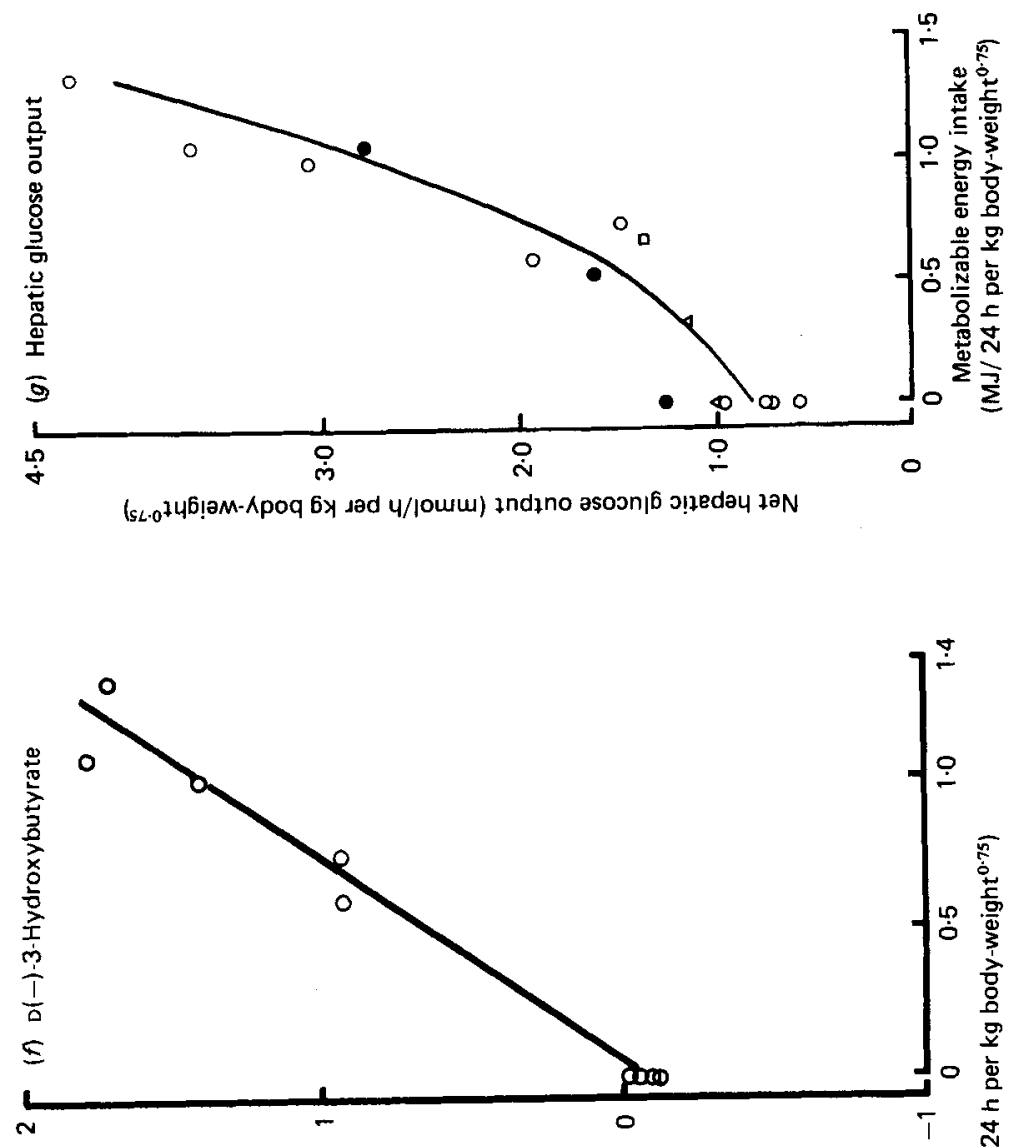

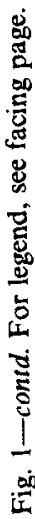

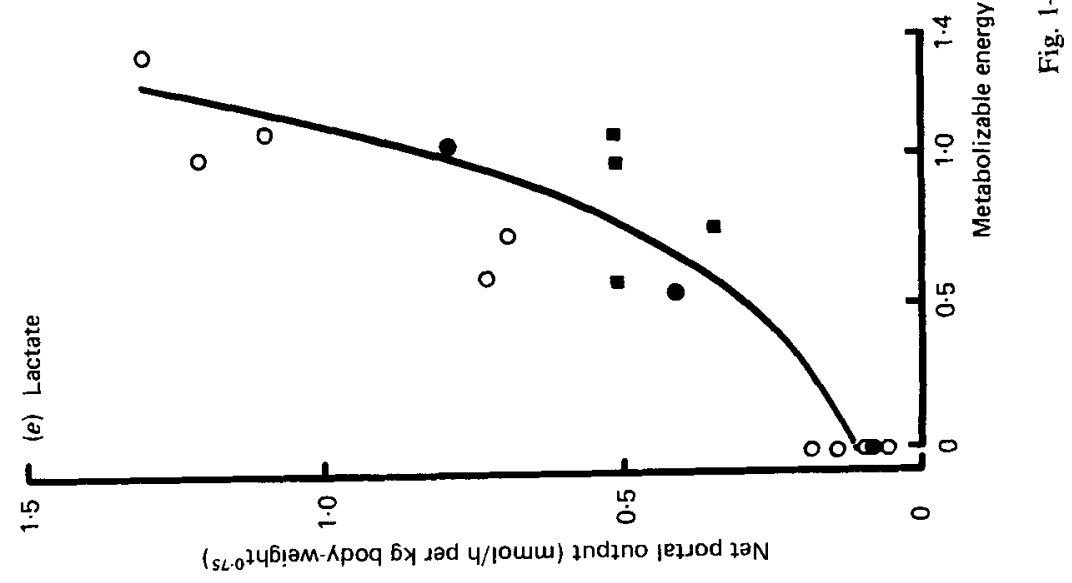




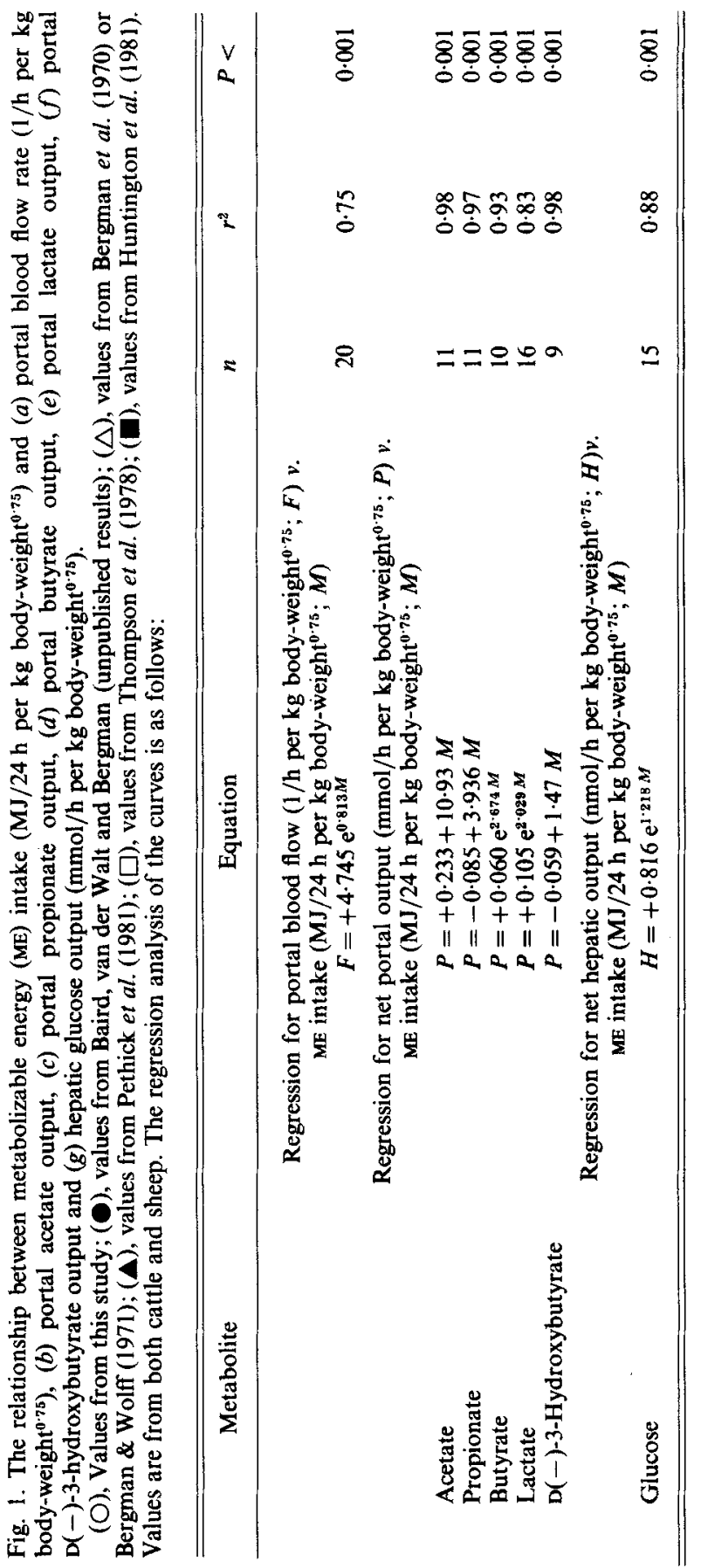


The authors are extremely grateful to $\mathrm{Dr} \mathrm{H}$. W. Symonds for catheterizing the animals and for carrying out measurements of $\mathrm{pO}_{2}$ and $\mathrm{pCO}_{2}$. They also thank Mrs Denise Mather, Mrs Vivien Bentley, Miss Jane Vickers and Mr R. A. Collins for skilled technical assistance. M.A.L. acknowledges receipt of an Agricultural Research Council Studentship.

\section{REFERENCES}

Baird, G. D. (1977). Biochem. Soc. Trans. 5, 819.

Baird, G. D. \& Heitzman, R. J. (1970). Biochem. J. 116, 865.

Baird, G. D. Heitzman, R. J., Reid, I. M., Symonds, H. W. \& Lomax, M. A. (1979). Biochem. J. 178, 35.

Baird, G. D., Lomax, M. A., Symonds, H. W. \& Shaw, S. R. (1980). Biochem. J. 186, 47.

Baird, G. D., Symonds H. W. \& Ash, R. (1975). J. agric. Sci., Camb. 85, 281.

Bauman, D. E., Davis, C. L. \& Bucholtz, H. F. (1971). J. Dairy Sci. 54, 1282.

Bensadoun, A., Paladines, O. L. \& Reid, J. T. (1962). J. Dairy Sci. 45, 1203.

Bergman, E. N., Katz, M. L. \& Kaufmann, C. F. (1970). Am. J. Physiol. 219, 785.

Bergman, E. N., Starr, D. J. \& Renlein, S. S. (1968). Am. J. Physiol. 215, 874.

Bergman, E. N. \& Wolff, J. E. (1971). Am. J. Physiol. 221, 586.

Bergmeyer, H. U., Bernt, E., Schmidt, F. \& Stork, H. (1974). In Methods of Enzymatic Analysis, 2nd ed., vol. 3. p. 1196 [H. U. Bergmeyer, editor]. London and New York: Academic Press.

Bernt, E. \& Bergmeyer, H. U. (1974). In Methods of Enzymatic Analysis, 2nd ed., vol. 4. p. 1704 [H. U. Bergmeyer, editor]. London and New York: Academic Press.

Bock, A. V., Field, H. \& Adair, G. S. (1924). J. biol. Chem. 59, 353.

Bruckental, I., Oldham, J. D. \& Sutton, J. D. (1980). Br. J. Nutr. 44, 33.

Costa, N. D., McIntosh, G. H. \& Snoswell, A. M. (1976). Aust. J. biol. Sci. 29, 33.

Eggstein, M. \& Kuhlmann, E. (1974). In Methods of Enzymatic Analysis, 2nd ed., vol. 4. p. 1825. [H. U. Bergmeyer, editor]. London and New York: Academic Press.

Garber, A. J., Menzel, P. H., Boden, G. \& Owen, O. E. (1974). J. clin. Invest. 54, 981.

Harvey, R. B. \& Brothers, A. J. (1962). Ann. N.Y. Acad. Sci. 102, 46.

Herbein, J. H., Van Maanen, R. W., McGilliard, A. D. \& Young, J. W. (1978). J. Nutr. 108, 994.

Huntington, G. B., Prior, R. L. \& Britton, R. A. (1981). J. Nutr. 111, 1164.

Katz, M. L. \& Bergman, E. N. (1969). Am. J. Physiol. 216, 946.

Lomax, M. A. (1979). Net portal and hepatic metabolism in the dairy cow in vivo. PhD Thesis, University of Reading.

Lund, P. (1974). In Methods of Enzymatic Analysis, 2nd ed., vol. 4. p. 1719. [H. U. Bergmeyer, editor]. London and New York: Academic Press.

Ministry of Agriculture, Fisheries and Food (1975). Tech. Bull. Minist. Agric. Fish. Fd no. 33.

Pennington, R. J. (1952). Biochem. J. 51, 251.

Pethick, D. W., Lindsay, D. B., Barker, P. J. \& Northrop, A. J. (1981). Br. J. Nutr. 46, 97.

Reid, I. M., Collins, R. A., Baird, G. D., Roberts, C. J. \& Symonds, H. W. (1979). J. agric. Sci., Camb. 93, 253.

Snoswell, A. M., Costa, N. D., McLean, J. G., Baird, G. D., Lomax, M. A. \& Symonds, H. W. (1978). J. Dairy Res. 45, 331.

Steel, J. W. \& Leng, R. A. (1973). Br. J. Nutr. 30, 475.

Symonds, H. W. \& Baird, G. D. (1973). Res. vet. Sci. 14, 267.

Thompson, G. E., Bassett, J. M. \& Bell, A. W. (1978). Br. J. Nutr. 39, 219.

Webster, A. J. F., Osuji, P. O., White, F. \& Ingram, J. F. (1975). Br. J. Nutr. 34, 125.

Weekes, T. E. C. \& Webster, A. J. F. (1975). Br. J. Nutr. 33, 425.

Williamson, D. H. (1974a). In Methods of Enzymatic Analysis, 2nd ed., vol. 4. p. 1679 [H. U. Bergmeyer, editor]. London and New York: Academic Press.

Williamson, D. H. (1974b). In Methods of Enzymatic Analysis, 2nd ed., vol. 3. p. 1727 [H. U. Bergmeyer, editor]. London and New York: Academic Press.

Wiltrout, D. W. \& Satter, L. D. (1972). J. Dairy Sci. 55, 307. 